\title{
Bronchial atresia with corresponding segmental pulmonary emphysema
}

\author{
L. K. L A C Q UE T ${ }^{1}, M$. F O R N H OF F, R. D I E R I C K X, \\ and N. BUYSSENS \\ Thoracic Centre, Adolf Stappaerts Clinic, and the Pathology Department, St. Elisabeth Clinic, \\ Antwerp, Belgium
}

This paper presents a 13-year-old boy suffering from congenital bronchial atresia of the anterior and apicoposterior segments of the left upper lobe with corresponding emphysema, and emphysema with bronchial atresia in the anterobasal segment of the left lower lobe. The aetiology of congenital localized emphysema is not always clear. In the group with a demonstrable check-valve mechanism, which permits air to enter but not to leave the lung, there is either internal stenosis or external compression of the bronchus. The condition is called idiopathic if no cause can be identified, but in some of these cases microscopical examination has disclosed alveolar fibrosis which prevents the rigid alveoli from collapsing on expiration. In these cases the check-valve mechanism exists at an alveolar level. In the small group of rare cases of bronchial atresia, air which enters through a collateral ventilation cannot be expired by the same route, and in these cases there is likewise a check-valve mechanism at an alveolar level; this is associated with the occurrence of localized emphysema, characterized by the presence of normal bronchial ramifications which arise from a bronchial sac with a blind proximal ending. The bronchial atresia is believed to occur after the 15th week of intrauterine life, probably as a result of vascular insufficiency. A preoperative diagnosis is possible on the basis of a plain chest radiograph, which shows the localized emphysema as well as an abnormal hilus shadow representing the mucus-filled blind bronchial stump; the diagnosis can be established also by a bronchogram, which shows a filling defect in the affected part of the lung. Surgical treatment is indicated.

Congenital pulmonary emphysema is a condition with which paediatricians and thoracic surgeons are now familiar.

Nelson (1932) was the first to focus attention on the serious nature of this condition in infants, in a report on a fatal case which occurred in a child aged 5.5 months. Royes (1938) was the first to mention localized lobar emphysema in an adult ; its cause was partial bronchial obstruction by a mucosal flap, an incidental finding at postmortem examination of an accident victim without pulmonary complaints. Overstreet (1939) focused attention on an anomaly of the lobar cartilage in a case of lobar emphysema. Gross and Lewis (1945) described the first patient with infantile lobar emphysema, who was successfully treated by lobectomy.

Numerous cases of localized emphysema have since been described, usually in infants with acute respiratory disorders. Raynor, Capp, and Sealy (1967) and Murray (1967) report series of 120 and

1Present address: Department of Thoracic, Cardiac and Vascular Surgery, Radboudzie-Kenhuis, Catholic University, Nijmegen, Holland of 166 cases, respectively. The difference in the number of cases and in the terminology between these two reviews must probably be ascribed to. a difference in diagnostic criteria.

In many cases the aetiology is obscure; it mustio be assumed, however, that all cases involve a? check-valve mechanism which permits air to enter but not to leave the lung. According to Stovin? (1959), lobar emphysema can be found in a groupo of cases with internal bronchial stenosis, a group with external bronchial compression, an idio- No pathic group in which no stenosis is found, andn a small group of unusual forms in which he in N cludes bronchial atresia.

We have personally observed a case of seg mental bronchial atresia with corresponding segmental emphysema in a boy aged 13 years. Thiss unusual form is not often described in the abun dant literature on localized emphysema. Similaro cases with bronchial atresia have been described by Belsey (1958), Simon and Reid (1963), Waddell $\stackrel{?}{\mathbb{P}}$ Simon, and Reid (1965), Hanna, Vattanapat, and Derrick (1969), and Vaghei (1970). 

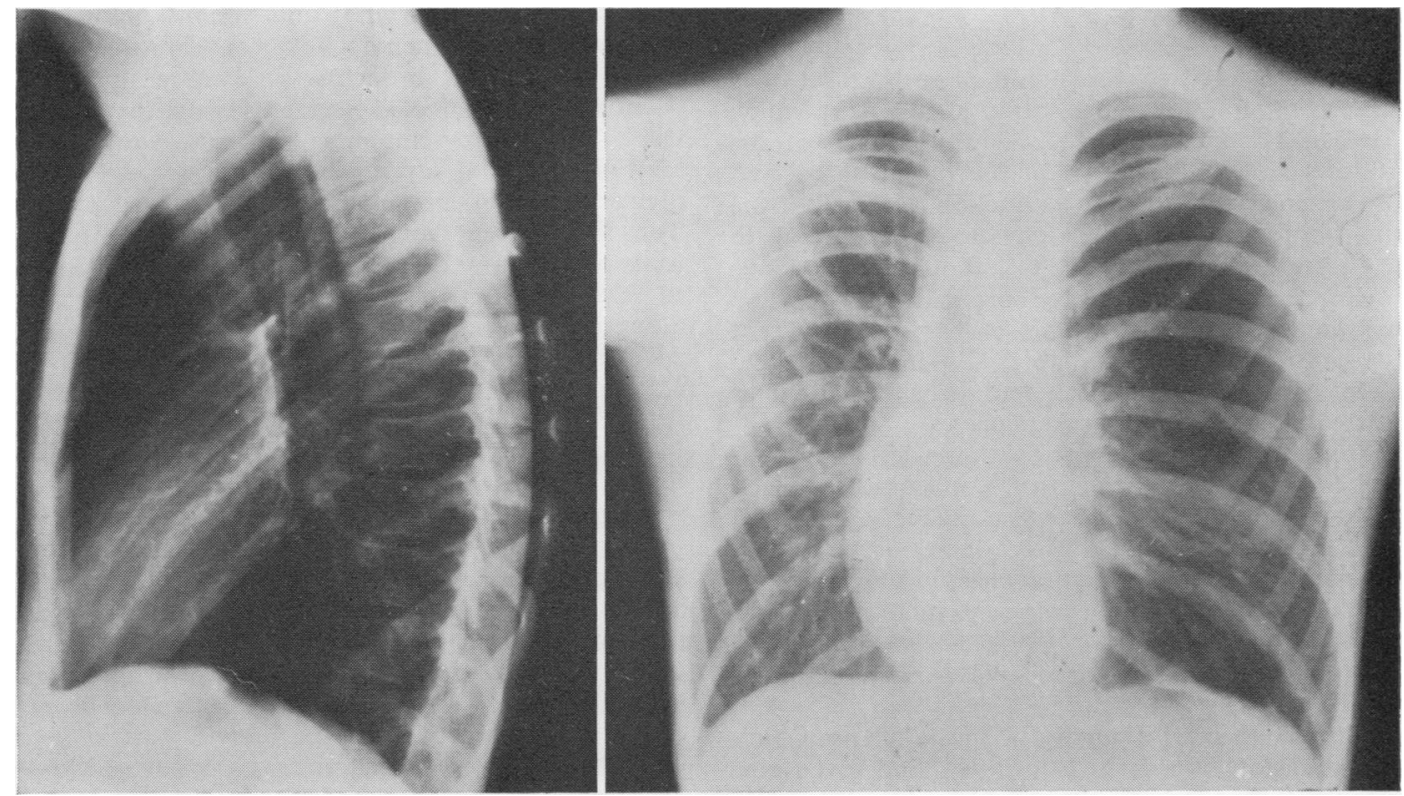

FIG. 1. Postero-anterior and lateral views of the chest in January 1969 show a localized pulmonary emphysema in the upper region of the left lung.
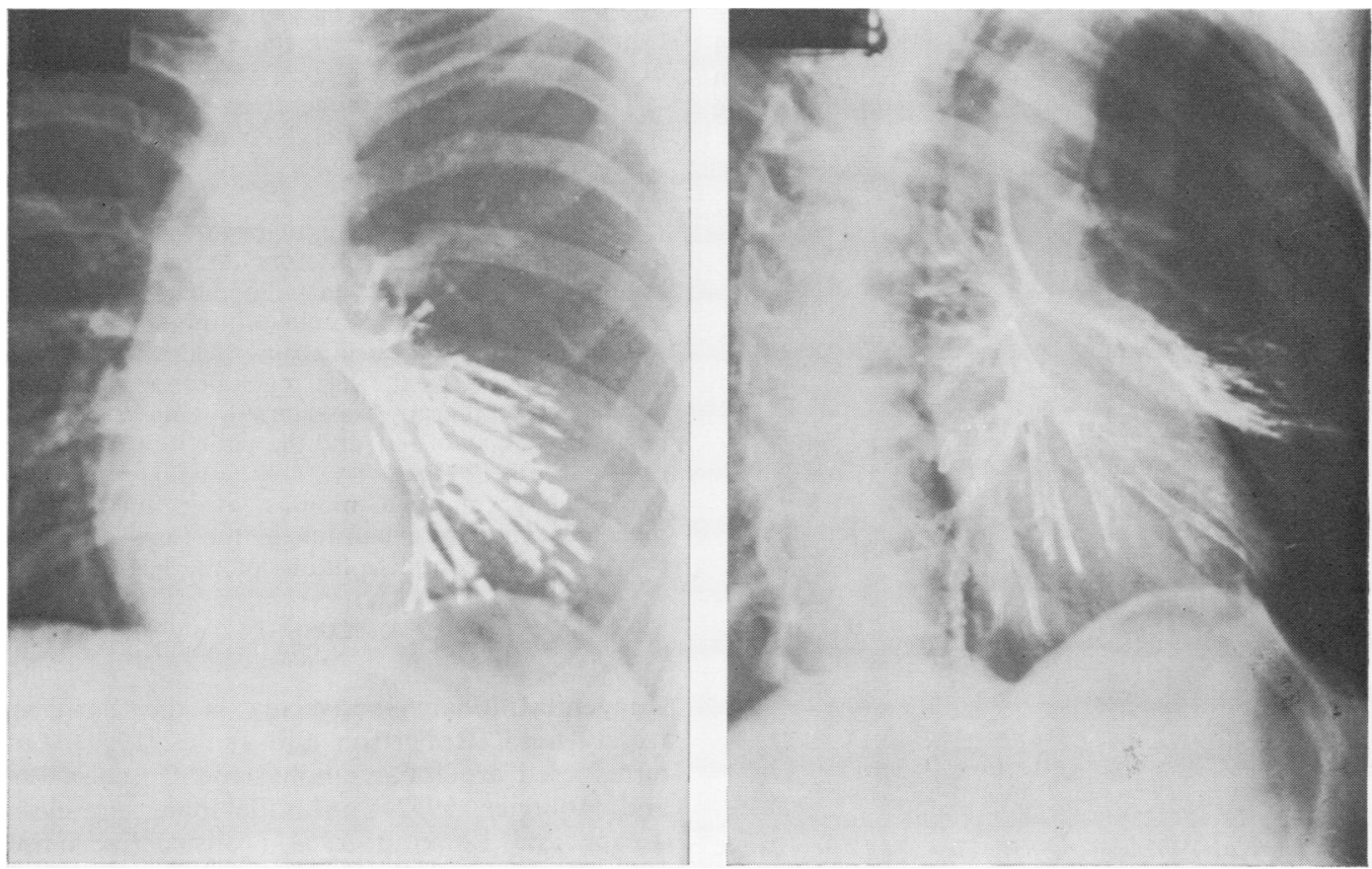

FIG. 2. Postero-anterior and oblique bronchographic views of the left lung in March 1969 show no filling of the bronchus of the culmen. 


\section{CASE REPORT}

V.M. R. aged 13 years was admitted to hospital on 4 February 1969 following a traffic accident in which he sustained concussion of the brain, lesions of the right forearm with paralysis of the radial nerve, and left-sided pneumothorax. After suction drainage of the pneumothorax, localized emphysema was found to exist in the upper region of the left lung.

Localized pulmonary emphysema had been detected in a school survey a few years earlier, and a recent chest radiograph was available (27 January 1969; Fig. 1). Hospital observation had been suggested at the time but had not yet taken place.

Radiographs and tomographs of the left lung confirmed the tentative diagnosis of 'congenital localized emphysema'. The left bronchogram (Fig. 2) showed adequate filling of the lower lobe bronchi and compression of the lingular branches, but no filling of the bronchus of the culmen, which gave an impression of obstruction.

Unfortunately, no bronchoscopic examination was made.

For this congenital anomaly of the left lung, which on the occasion of a traumatic injury had given rise to pneumothorax as a complication, surgical treatment was suggested and carried out on 24 March 1969 through a left thoracotomy. It disclosed localized emphysema of the three upper segments of the left upper lobe (culmen) and in the anterobasal segment of the left lower lobe. These segments were a pale pink colour, felt like foam-rubber and protruded immediately after the thoracotomy (Fig. 3). Dissection of the hilus of the upper lobe and of the lower lobe

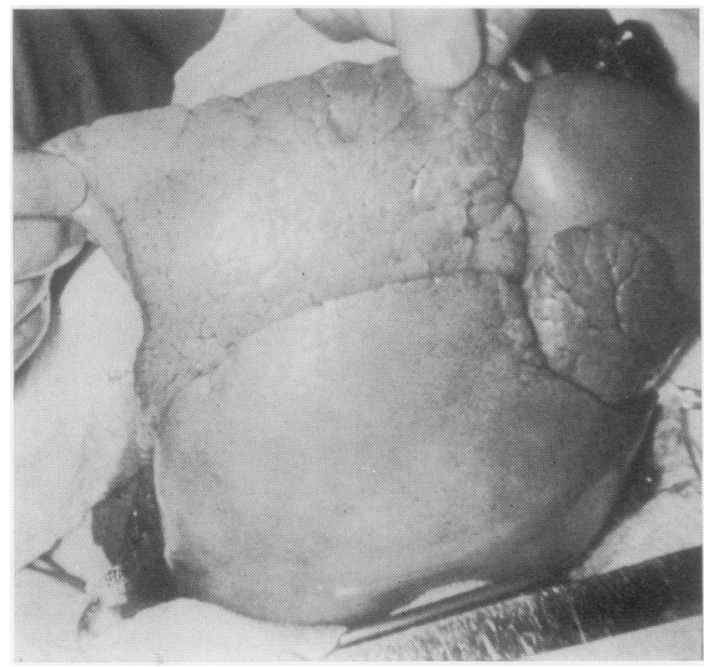

FIG. 3. Operative view of the left lung discloses a localized pulmonary emphysema in the three upper segments of the left upper lobe and in the anterobasal segment of the left lower lobe. revealed a normal arterial and venous blood supply to the affected segments; however, careful dissection failed to reveal a bronchus or even a fibrous con흠 nection of the affected segments with the bronchiakn tree. The emphysematous segments were resectedo after ligation and severance of the vessels. These seg ments retained their air volume and floated on wateros The lingular cut surface, via which the air supply $\overrightarrow{0}$ took place, showed a very large air leakage. In orderto save the lingula, this was closed upon itself; an $\vec{w}$ attempt to expand the compressed lingula was? successful.

Pathological anatomical examination of thơ resected emphysematous segments disclosed no bronchi in the hilar cut surface. The pulmonary $\vec{\circ}$ tissue had a smooth surface, was greyish-red ando showed no anthracosis.

Examination of thin sections cut after fixationshowed that both resected specimens contained immediately below the hilus, a cystically distended? thin-walled bronchus which ramified into moderately distended smaller bronchi, filled with accumulated mucus. The wall of the cystically distended bronchus consisted in part of cartilage and in part of a thin layer of connective tissue which was covered by one or several layers of cylindrical epithelium.

Since the bronchial wall was not demonstrable in the hilus, it may be concluded that the proximal par of the bronchus had a blind ending.

The smaller bronchi were markedly distended anco filled with mucus; they had one or several layers of cylindrical epithelium and a thin wall which consisted $\overline{\vec{b}}$ of collagenous tissue.

The alveoli showed moderately diffuse emphysema without lesions of the interalveolar septa.

There were no inflammatory lesions, and the vessel were normal.

There was only very slight postoperative air leak age, and drainage was therefore discontinued after 480 hours. Persistent atelectasis of the lingula then occurred so that no complete filling of the thora was achieved. A bronchoscopic follow-up disclosec? marked oedema of the left main bronchus for which corticosteroid therapy was started. This gradually lec? to improved expansion, and the patient was discharged on 30 April 1969.

A radiograph five months after the operation revealed complete expansion of the remainder of the left lung with complete filling of the left hemithoran (Fig. 4).

\section{DISCUSSION}

Congenital lobar emphysema is the term $\operatorname{mos}{ }^{0}$ widely used (Robertson and James, 1951). Othep terms used are lobar emphysema (Fischer, Potts; and Holinger, 1952); infantile lobar emphysema (Leape and Longino, 1964) ; obstructive emphy sema (Lewis and Potts, 1951); lobar obstructive. emphysema (Sloan, 1953); regional obstructive emphysema (Thomson and Forfar, 1958); cons 

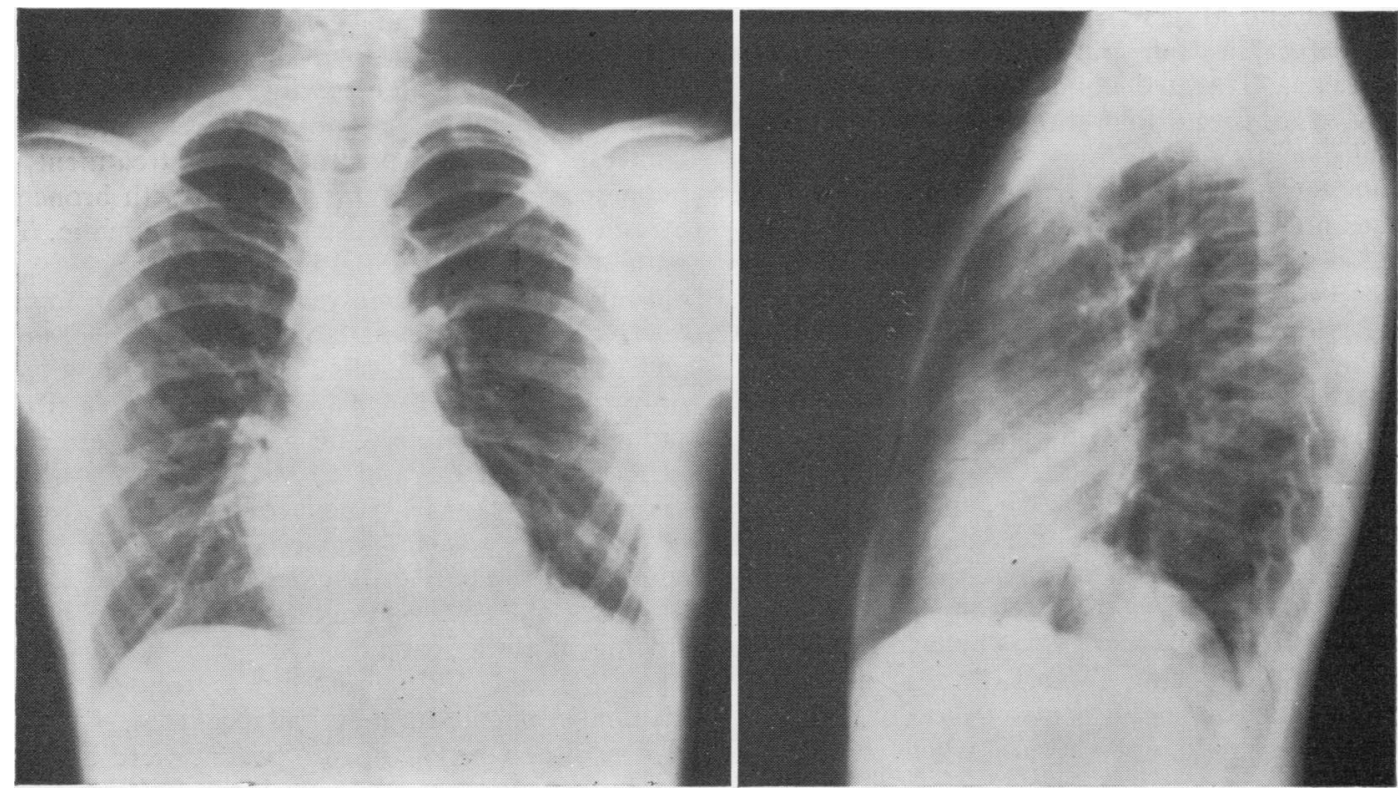

FIG. 4. Postero-anterior and lateral views of the chest 5 months after surgery show complete expansion of the remainder of the left lung with complete filling of the left hemithorax.

genital obstructive emphysema (DeBord and Sibilsky, 1954); progressive infantile emphysema (Ehrenhaft and Taber, 1953) ; tension emphysema (Nelson and Reye, 1954); lobar tension emphysema (Binet, Nezelof, and Fredet, 1962) ; congenital localized emphysema (Campbell, Bauer, and Hewlett, 1961); localized hypertrophic emphysema (Shaw, 1952); localized pulmonary hypertrophic emphysema (Williams, 1952); and congenital hypertrophic emphysema (Hamilton and Gillespie, 1958).

Since none of these exactly describes the situation which prevailed in our case, we prefer the description 'bronchial atresia with corresponding segmental pulmonary emphysema'.

The aetiology can be explained when an internal or an external cause can be identified. In other cases there is no unequivocal aetiological factor.

Internal causes are reported by Raynor et al. (1967) to be involved in $38 \%$ of cases. They usually consist of anomalies of the cartilage rings -absence, hypoplasia or abnormal softness (bronchomalacia). A survey of the literature shows that these anomalies have been described by Overstreet (1939), Fischer et al. (1952), Shaw (1952), Sloan (1953), Bolande, Schneider, and Boggs (1956), Holzel, Bennett, and Vaughan (1956), Mathey, Binet, and Galey (1956), Cottom and Myers (1957), Nelson, T. Y. (1957), Stovin (1959), and Moyson, Desmul, and Cremer (1962).

Other possible internal causes are the presence of a mucosal flap (Royes, 1938) and hypertrophy of bronchial mucosa resulting in the formation of a fold which serves as a valve during inspiration (Robertson and James, 1951; Fischer et al., 1952). According to Raynor et al. (1967), this mucosal fold is present in $13 \%$ of cases but is often overlooked in the resected specimen because it often coincides with the site of bronchial section. Mention has been made also of bronchial kinking secondary to herniation through an anterior mediastinal defect (Gross and Lewis, 1945 ; Lewis and Potts, 1951) and of the presence of a cartilaginous septum in the bronchus (Drift, Waldeck, and Van Rooden, 1956).

External causes are reported by Raynor et al. (1967) to be involved in $8 \%$ of cases. External compression of a main bronchus or a lobar bronchus may have a vascular cause: patent ductus arteriosus (Fischer et al., 1952-2 out of 6 cases; Bolande et al., 1956; Cottom and Myers, 1957); aneurysm of a pulmonary vein (Robertson and James, 1951); or an abnormal pulmonary artery (Potts, Holinger, and Rosenblum, 1954; Morse and Gladding. 1955 ; Belsey, 1958 ; Contro, Miller, White, and Potts, 1958a,b ; Sherman, 1959). 
Cottom and Myers (1957) reported a congenital heart defect in four out of six cases of lobar emphysema. The two conditions are best treated jointly, if possible, first the pulmonary and then the cardiac anomaly.

The term idiopathic emphysema is used if neither an internal stenosis nor an external compression of the bronchus is found. In the majority of cases (about $55 \%$ according to Raynor et al., 1967) pathological examination fails to disclose a bronchial cause of the emphysema.

The condition has been ascribed to rupture of the alveoli due to excessive inflation at postpartum artificial respiration (Robertson and James, 1951 ; Shaw, 1952; Ehrenhaft and Taber, 1953). The occurrence of a bulla might so be explained, but it is not clear why the emphysema remains confined to one lobe or to a few segments.

Mayer and Rappaport (1953) believed that there must be predisposing factors in the pulmonary parenchyma for emphysema to occur, because normal alveoli do not rupture when exposed to physiological pressures. Bolande et al. (1956) established an increase in collagenous tissue in the alveolar wall, giving rise to 'alveolar fibrosis'. During inspiration the fibrous alveoli distend, but they are too rigid to collapse at expiration, and emphysema results. However, it is not certain that this alveolar fibrosis is the cause; it can be a secondary occurrence. Leape and Longino (1964) likewise reported this 'fibrous dysplasia' in several of their patients.

Zatzkin, Cole, and Bronsther (1962) suggested a division into hypertrophic and obstructive forms, and maintained that the designation 'congenital hypertrophic lobar emphysema' should be reserved for cases in which the alveolar anomaly is regarded as the causative factor.

The unusual forms of lobar emphysema include those associated with localized bronchial neuromuscular dysfunction (Williams, 1952; Sloan, 1953 ; Holzel et al., 1956). A second unusual form is that associated with bronchial atresia, as described by Belsey (1958: 1 case); Simon and Reid (1963: 3 cases); Waddell et al. (1965: 2 cases); Hanna et al. (1969: 1 case); Vaghei (1970: 2 cases) and the case presented here.

In the cases with bronchial atresia the air supply to the corresponding segments takes place through alveolar communications with the normal lung tissue. Air thus inspired cannot be evacuated by the same route; this is prevented by a checkvalve mechanism which can be localized at an alveolar level. Localized pulmonary emphysema results. The concomitant presence of alveolar fibrosis has been demonstrated only in the case of $\stackrel{\stackrel{\vec{F}}{+}}{+}$ Hanna et al. (1969).

Unlike other patients with lobar emphysema, $\frac{\bar{c}}{\bar{c}}$ who usually show pronounced respiratory dis- $\frac{\widehat{\sigma}}{\phi}$ comfort and are presented for treatment as $\odot$ neonates or young infants, patients with bronchialis atresia are older and usually asymptomatic. The $\vec{\circ}$ patient described by Belsey (1958) was $6 \frac{1}{2}$ years old and had only a one-year history of an unpro- $\vec{\omega}$ ductive cough; the patients discussed by Simon? and Reid (1963) were 19, 25 and 18 years old, and $\vec{x}$ only the last-mentioned patient showed recurrent命 pulmonary infections; the patients of Waddell $e t-$ al. (1965) were 25 and 16 years old and showedo no symptoms; the patient described by Hannao et al. (1969) was a 7-year-old boy without symp-toms; the patients of Vaghei (1970) were 13 and 36 years old and the condition was an incidentaE finding in these patients. Our patient was a boy aged 13, and the condition was treated after a traumatic pneumothorax had occurred.

The sites affected in our patient were both theleft upper and the left lower lobes. The left uppero lobe was affected in the cases reported by Belseys (1958), Simon and Reid (1963), and Waddell et al (1965). The middle lobe was affected in the cas@ reported by Hanna et al. (1969), and the left and right upper lobes were affected in the cases reported by Vaghei (1970).

Fischer et al. (1952) reported that localize emphysema is most likely to affect the upper lobe and the middle lobe, and they ascribed this to the stronger influence of the diaphragm and lower ribs on the lower lobes during expiration. This explane ation is plausible for the idiopathic group, is which the anomaly should be at an alveolar leveß but not for the group with obstruction or atresia for bronchial anomalies are most common i upper lobe bronchi (Holzel et al., 1956) and the vascular anomalies with their invariable localiza? tion in the upper mediastinum can exert aw influence only on the upper lobe bronchi. Accord ing to Boyden (1955), most congenital bronchiâ anomalies occur in the left upper lobe, and thepo result from an embryological instability ratheri than from mechanical causes.

Bucher and Reid (1961) ascribed the occurrence of bronchial atresia to a disorder in the vasculart zation, not at the time of development of the lobax bronchus but at a later stage-after the 15 th week of intra-uterine life, when the bronchial tree has already attained its full ramification. The atresia therefore, develops upon a previously normal a passage, and the distal bronchi consequently show normal development. The corresponding sege 
mental or lobar emphysema is characterized by the presence of normal bronchial branches, arising from a bronchial sac with a blind proximal ending.

According to Waddell et al. (1965) and Vaghei (1970), bronchial atresia with corresponding emphysema can be diagnosed on the basis of standard chest radiographs, which reveal a butterfly shadow in the hilus, suggestive of a mucusfilled bronchial sac, and emphysema in the corresponding segments or lobe.

Unless the patients are severely ill and dyspnoeic infants, bronchoscopy and bronchography can supply useful information. In older children, in particular, the possibility of an intrabronchial foreign body must be taken into consideration; and this possibility must be ruled out before a decision in favour of surgery can be made. In the rare cases of bronchial atresia, the absence of a bronchus or the presence of a vestigial depression can be established.

Bronchography gives useful information also in all cases involving bronchial anomalies, internal stenosis or external compression. Unfortunately, we omitted bronchoscopy in our case and obtained only a bronchogram. This revealed a filling defect of the culmen, which was ascribed to internal bronchial stenosis caused by a cartilaginous or mucosal anomaly, with localized emphysema as a result. The presence of bronchial atresia with pulmonary emphysema was not suspected. In retrospect, we advise preoperative bronchoscopic examination. When the diagnosis is dubious, diagnostic aspiration must be avoided because it may give rise to a pneumothorax which only aggravates the respiratory discomfort.

There can be no doubt about the surgical indication in infants with localized emphysema and pronounced respiratory discomfort due to compression of intact lung parts; but the treatment of an incidentally found emphysema in an older child is open to discussion. We believe that surgery is indicated in these cases also, unless they involve post-infectious pneumatoceles which will absorb spontaneously. In our patient a complication-pneumothorax caused by a blunt chest injury without costal fractures-led to establishment of the diagnosis and operation.

\section{REFERENCES}

Belsey, R. H. R. (1958). Tension cysts of the lung in infancy and childhood. Brit. J. Tuberc., Dis. Chest., $52,53$.

Binet, J. P., Nezelof, C., and Fredet, J. (1962). Five cases of lobar tension emphysema in infancy; importance of bronchial male formation and value of postoperative steroid therapy. Dis. Chest. 41, 126.
Bolande, R. B., Schneider, A. F., and Boggs, J. D. (1956). Infantile lobar emphysema. Arch. Path., 61, 289.

Boyden, E. A. (1955). Segmental Anatomy of the Lungs. A Study of the Patterns of the Segmental Bronchi and Related Pulmonary Vessels. McGraw-Hill, New York.

Bucher, U., and Reid, L. (1961). Development of the intrasegmental bronchial tree: the pattern of branching and development of cartilage at various stages of intra-uterine life. Thorax, 16, 207

Campbell, D., Bauer, A. J., and Hewlett, T. H. (1961). Congenital localized emphysema. J.' thorac. Surg., 41, 575.

Contro, S., Miller, R. A., White, H., and Potts, W. J. (1958a). Bronchial obstruction due to pulmonary artery anomalies. I. Vascular sling. Circulation, 17, 418.

artery anomalies (1958b). Bronchial obstruction due to pulmonary 424.

Cottom, D. G., and Myers, N. A. (1957). Congenital lobar emphysema. Brit. med. J., 1, 1394

DeBord, R. A., and Sibilsky, C. E. (1954). Congenital obstructive emphysema treated by lobectomy. Amer. J. Dis. Child., 88, 775

Drift, L. Van der, Waldeck, K., and Van Rooden, K. (1956). Lobar emphysema in early childhood. Arch. chir. neerl., 8, 73.

Ehrenhaft, J. L., and Taber, R. E. (1953). Progressive infantile emphysema: a surgical emergency. Surgery, 34, 412.

Fischer, H. W., Potts, W. J., and Holinger, P. H. (1952). Lobar emphysema in infants and children. J. Pediat., 41, 403.

emphysema in infants and children. J. Pediat., 41, 403 .
Gross, R. E., and Lewis, J. E. (1945). Defect of anterior mediastinum; successful surgical repair. Surg. Gynec. Obstet., 80, 549.

Hamilton, L. C., and Gillespie, R. W. (1958). Congenital hypertrophic emphysema. Amer. J. Roentgenol., 80, 421.

Hanna, E. A., Vattanapat, S., and Derrick, J. R. (1969). Congenital lobar emphysema with bronchial atresia. Ann. thorac. Surg., 7, 357.

Holzel, A., Bennett, E., and Vaughan, B. F. (1956). Congenital lobar emphysema. Arch. Dis. Childh., 31, 216.

Leape, L. L., and Longino, L. A. (1964). Infantile lobar emphysema. Pediatrics, 34, 246.

Lewis, J. E., and Potts, W. J. (1951). Obstructive emphysema with a defect of the anterior mediastinum. J. thorac. Surg., 21, 438.

Mathey, J., Binet, J. P., and Galey, J. J. (1956). Traitement chirurgicale de l'emphysème pulmonaire localisé du nourrisson et de l'enfant. Arch. franc. Pédiat., 13, 113.

Mayer, E., and Rappaport, I. (1953). Clinical observations and interpretations of abnormal air spaces in the lungs: a new concept of their origin. J. Amer. med. Ass., 153, 700.

Morse, H. R., and Gladding, S. (1955). Bronchial obstruction due to misplaced left pulmonary artery. Amer. J. Dis. Child., 89, 351.

Moyson, F., Desmul, A., and Cremer, N. (1962). L'emphysème lobaire obstructif chez le nourrisson. Acta paediat. belg., 16, 235.

Murray, G. F. (1967). Congenital lobar emphysema-collective review. Surg. Gynec. Obstet., 124, 611 .

Nelson, R. L. (1932). Congenital cystic disease of the lung. J. Pediat. $1,233$.

Nelson, T. Y. (1957). Tension emphysema in infants. Arch. Dis.,

Childh., 32, 38 . (1954). Tension emphysema: a surgical emergency in infants. Med. J. Aust., 2, 342.

Overstreet, R. M. (1939). Emphysema of a portion of the lung in the early months of life. Amer. J. Dis. Child., 57, 68.1.

Potts, W. J., Holinger, P. H. and Rosenblum, A. H. (1954). Anomalous left pulmonary artery causing obstruction to right main bronchus. J. Amer. med. Ass., 155, 1409.

Raynor, A. C., Capp, M. P., and Sealy, W. C. (1967). Lobar emphysema of infancy. Diagnosis, treatment, and etiological aspectscollective review. Ann. thorac. Surg., 4, 374.

Robertson, R., and James, E. S. (1951). Congenital lobar emphysema. Pediatrics, 8, 795.

Royes, K. (1938). Localized hypertrophic emphysema. Brit. med. J., 2, 659 .

Shaw, R. R. (1952). Localized hypertrophic emphysema. Pediatrics, 9, 220 .

Sherman, F. E. (1959). Anomalous course of left pulmonary artery: a cause of obstructive emphysema in infants. J. Pediat., 54, 93.

Simon, G., and Reid, L. (1963). Atresia of an apical bronchus of the left upper lobe-report of three cases. Brit. J. Tuberc. Dis. Chest, $57,126$.

Sloan, H. (1953). Lobar obstructive emphysema in infancy treated by lobectomy. J. thorac. Surg., 26, 1.

Stovin, P. G. I. (1953). Congenital lobar emphysema. Thorax, 14, 254.

Thomson, J and Forfar J O (1958). Regional obstructive emphysema in infancy. Arch Dis. Childh., 33, 97.

Vaghei, R. (1970). Bronchial atresia of upper lobe of the lung. Chest, 57,91 .

Waddell, J. A., Simon, G., and Reid, L. (1965). Bronchial atresia of the left upper lobe. Thorax, 20, 214

Williams, M. H. (1952). Localized pulmonary hypertrophic emphysema. J. thorac. Surg., 24, 522

Zatzkin, H. R., Cole, P. M., and Bronsther, B. (1962). Congenital hypertrophic lobar emphysema. Surgery, 52, 505. 